einstein

Official Publication of the Instituto Israelita

de Ensino e Pesquisa Albert Einstein

ISSN: 1679-4508 | e-ISSN: 2317-6385

\title{
What is the role of heat shock protein in abdominal organ transplantation?
}

\author{
Igor Lepski Calii', Francisco Tustumi², Jorge Henrique Bento de Sousa', \\ Bruno Martins Tomazini ${ }^{3}$, Ruy Jorge Cruz Jr', Gustavo Niankowski Saliba', \\ Rafael Antonio Arruda Pécora', Luiz Augusto Carneiro D'Albuquerque² \\ Hospital Israelita Albert Einstein, São Paulo, SP, Brazil \\ 2 Faculdade de Medicina, Universidade de São Paulo, São Paulo, SP, Brazil. \\ ${ }^{3}$ Hospital Sírio-Libanês, São Paulo, SP, Brazil. \\ ${ }^{4}$ School of Medicine, University of Pittsburgh, Pittsburgh, PA, USA.
}

DOI: 10.31744/einstein_journal/2022RB6181

\section{ABSTRACT}

Ischemia-reperfusion injury is a pathophysiological event occuring after abdominal organ transplantation, and has a significant influence on prognosis and survival of the graft. It is involved in delaying the primary function or non-functioning of the graft. The objective of this study was to provide information on heat shock protein mechanisms in ischemia-reperfusion injuries in abdominal organ transplantations, and to indicate the possible factors involved that may influence the graft outcome. Several classes of heat shock proteins are part of the ischemia and reperfusion process, both as inflammatory agonists and in protecting the process. Studies involving heat shock proteins enhance knowledge on ischemia-reperfusion injury mitigation processes and the mechanisms involved in the survival of abdominal grafts, and open space to support therapeutic future clinical studies, minimizing ischemia and reperfusion injuries in abdominal organ transplantations. Expression of heat shock proteins is associated with inflammatory manifestations and ischemiareperfusion injuries in abdominal organ transplantations and may influence graft outcomes.

Keywords: Reperfusion injury; Heat-shock proteins; Kidney transplantation; Liver transplantation; Organ transplantation

\section{INTRODUCTION}

How to cite this article:

Calil IL, Tustumi F, de Sousa JH,

Tomazini BM, Cruz Jr RJ, Saliba GN, et al. What is the role of heat shock protein in abdominal organ transplantation? einstein (São Paulo). 2022;20:eRB6181.

\section{Corresponding author: \\ Francisco Tustumi \\ Avenida Dr. Enéas Carvalho de Aguiar, 255 Cerqueira César \\ Zip code: 05403-000 - São Paulo, SP, Brazil \\ Phone: (55 11) 2661-0000 \\ E-mail: franciscotustumi@gmail.com}

Received on:

Sep 11, 2020

\section{Accepted on:}

Feb 13, 2021

\section{Copyright 2022}

\section{Heat shock proteins}

Heat shock proteins (HSP) are part of a large family of proteins and are found in virtually all organs and tissues. ${ }^{(1)}$ Heat shock proteins are essential in a wide variety of intracellular processes, such as protein folding, assembly, disassembly and intracellular localization; and secretion, regulation and degradation of other proteins. ${ }^{(2,3)}$ They have an important protective role, both under stress-free conditions, ${ }^{(4)}$ and during ischemic or oxidative stress, inflammatory processes, intracellular energy depletion, hormonal processes, apoptosis, among others. ${ }^{(2,5)}$ These stress factors occur in patients undergoing abdominal organ transplantation, and the ability to withstand such stressors is closely linked to the success of the procedure.

When the blood supply to a tissue is interrupted, a sequence of biochemical events is initiated, leading to cell dysfunction and death. Restoring blood flow is a prerequisite for recovery from ischemic injury. However, reperfusion can induce more local tissue damage. ${ }^{(6)}$ This injury is at the pathophysiological basis of several serious diseases, including myocardial infarction, stroke, tissue damage induced by surgical procedures and organ transplantation.(7) Understanding HSPs could contribute to the development of clinical interventions capable of reducing the extent of ischemia-reperfusion (I/R) injury, such as in organ transplantations. 
Ischemia-reperfusion injury is a pathophysiological event that occurs after abdominal organ transplantation and has a significant influence on the prognosis of graft function. The mechanisms of this injury remain unclear. Several factors are associated with the I/R injury process, including anaerobic metabolism, oxidative stress, intracellular calcium overload, innate immune responses, activated cytokines and chemokines. ${ }^{(8)}$

In abdominal organ transplantation, $\mathrm{I} / \mathrm{R}$ is essential for graft survival and is involved in different injuries, such as late graft function and primary non-function of the graft. The discrepancy between supply and demand for donors has led to an increase in transplantation of marginal organs, such as extended criteria donors, and donation after cardiac death. ${ }^{(9)}$ Such marginal organs are more susceptible to I/R injury. ${ }^{(10-12)}$

Heat shock proteins are described as intracellular chaperones of aberrant denatured, non-native and denatured proteins, and are involved in cytoprotection and adaptation for cell survival in response to stressful stimuli. Under more intense stress, HSPs are released into the extracellular environment, as cytokines, and can be called chaperokines. The chaperokine activity of HSPs is mediated, in part, by the interaction with toll-type receptors, leading to the activation of different immunological pathways, such as acute rejection, chronic rejection, and I/R injury. ${ }^{(13-17)}$

The objective of this review was to provide information on the mechanisms of HSP in I/R injury in abdominal organ transplantations, and to indicate the possible factors involved that may influence the graft outcome. Studies involving HSPs allow for greater knowledge on the processes controlling attenuation of $\mathrm{I} / \mathrm{R}$ injuries and the mechanisms involved in the survival of abdominal grafts, and open space to support future clinical therapeutic studies, minimizing $\mathrm{I} / \mathrm{R}$ injuries in abdominal organ transplantations.
This is a narrative review of the literature, evaluating the mechanisms involved in HSP in I/R injuries in abdominal organ transplantations. The databases consulted were PubMed ${ }^{\circledR}$, Latin American and Caribbean Literature in Health Sciences (LILACS), and Embase. The keywords searched were "ischemia", "transplantation", "reperfusion injury", "nitric oxide", "heat-shock protein", "HSP", "liver", "kidney", "pancreas", "islets of Langerhans", "intestine" and "bowel". All references were reviewed to retrieve additional articles.

\section{Historical aspects}

Researching the salivary glands of drosophilae, Ritossa described, for the first time, in 1962, a group of proteins, whose expression was modified with temperature shocks. Such proteins would be called "heat shock proteins". ${ }^{(18)}$

Later, it was discovered that, in addition to temperature shock, several stressful situations could induce such alterations in the chromosomal areas associated with the synthesis of HSP. Ritossa demonstrated that 2,4-dinitrophenol could induce an increase in HSP synthesis. ${ }^{(18)}$ In 1976, Koninkx, in addition to 2,4-dinitrophenol, investigated arsenite, vitamin B6, and anaerobiosis and demonstrated all these stressors could induce an increase in the HSP synthesis rate. ${ }^{(19)}$

Since then, the scientific community had great interest in investigating the role of such proteins in the response to stress situations.

\section{FAMILIES OF HEAT SHOCK PROTEINS}

Heat shock proteins are usually named according to the size of their monomers. ${ }^{(20)}$ They can be grouped into the following protein families: ${ }^{(1)}$ HSP110, HSP90, HSP70, HSP40, small HSPs, and human chaperonin families (Table 1). The different families of HSPs work together.

Table 1. Heat shock protein families

\begin{tabular}{lcr}
\hline Family & \multicolumn{1}{c}{ Cellular location } & Function \\
\hline HSP90 & Cytosol, nucleus, endoplasmic reticulum, and mitochondria & Signal transduction; cell proliferation; protein folding \\
HSP70 and HSP110 & Cytosol, nucleus, endoplasmic reticulum, and mitochondria & Anti-apoptotic activity; signal transduction; cell proliferation; intracellular transport \\
Human chaperonines & Mitochondria and cytosol & Protein stability; protein folding \\
HSP40 & Nucleus & Cofactor for HSP70 ATPase activity \\
Small HSPS & Cytosol & Anti-apoptotic activity; actin filament stabilization
\end{tabular}




\section{ROLE OF HEAT SHOCK PROTEINS IN ORGAN TRANSPLANTATION}

The stressful environment caused by $\mathrm{I} / \mathrm{R}$ injuries in transplantations stimulates the synthesis of HSPs, which would have a protective role on transplanted organs. ${ }^{(13-17)}$ In studies on dynamic organ preservation methods, Minor et al. and von Horn et al. ${ }^{(21,22)}$ demonstrated that short hyperthermic impulses could induce HSP synthesis, which, in turn, causes a reduction in the degradation of mitochondrial enzymes and an increase in bile production after reperfusion.

Therefore, HSPs could be considered prognostic biomarkers in organ transplantations. The mapping of I/R-related biomarkers points to possible organ conditioning during normal or hyperthermic dynamic preservation methods. ${ }^{(23,24)}$

\section{Intestinal transplantation}

Intestinal transplantation is an accepted treatment for patients with irreversible and complicated bowel failure. However, it is characterized by higher acute and severe rejection rates among abdominal organ transplantations. ${ }^{(25)}$ Through the interaction of innate and adaptive immunological systems, I/R injury exacerbates the alloimmune response. ${ }^{(26-28)}$

Acute rejection is the most important factor in determining the survival of intestinal allografts. ${ }^{(29)}$ Ogita et al. ${ }^{(29)}$ evaluated the expression of HSP60 and HSP70 in the graft and in the native bowel after heterotopic small bowel transplantation in rats. They demonstrated that HSP expression is induced after small bowel transplantation, and its induction has both immunological and non-immunological components. They also showed that HSPs are induced in the native bowel, and expression in the graft and in the recipient bowel is only partially inhibited by the administration of tacrolimus immunosuppression.

In animal experiments, Oltean et al. ${ }^{(30)}$ observed a direct relation between the expression of HSP60 and immune activation, which reflects in the degree of rejection. The hypothesis that the increase in HSP60 is due to immunological causes is consistent with the observation that the increase in HSP60 was seen only in the allogeneic combination. Furthermore, the increase was clear in the crypt area, the same place where rejection becomes more exacerbated. Oxidative stress and inflammation are the driving forces of intestinal $\mathrm{I} / \mathrm{R}$ injury. ${ }^{(12)}$ Consequently, intestinal $\mathrm{I} / \mathrm{R}$ is also expected to activate anti-inflammatory pathways, such as HSPs, to regulate the inflammatory response to injury. ${ }^{(31)}$
In an experimental model, Vincenti et al. ${ }^{(32)}$ demonstrated that HSP32 and HSP70 inflammatory response is similar when an arterial clamping is performed, compared to when a venous occlusion is performed.

\section{Liver transplantation}

When stimulated by environmental stress factors, cells expressing HSP70 can survive even under conditions that would normally be lethal to them. ${ }^{(33)}$ Thus, HSP70 can be a potential prognostic biomarker in liver transplantation. Animal models have shown that liver preconditioning, such as by transient clamping of the hepatic pedicle, (Pringle maneuver), can induce increased expression of HSP70, thus leading to tolerance to I/R lesions. ${ }^{(34,35)}$

Conti et al. ${ }^{(36)}$ evaluated gene expression levels in reperfused livers compared to baseline values before the removal of donor organs. They observed that 795 genes had their expression modified by the $\mathrm{I} / \mathrm{R}$ lesion, wherein $12.5 \%$ of genes were related to the inflammatory process and $12 \%$ to apoptotic process. The genes that encode HSPs accounted for $22.5 \%$ of total set of genes that had their expression modified. The most regulated genes were HSP70, HSP105, and HSP90.

Different experimental models in rats have shown that preconditioning influences the production of HSP, especially HSP72 and HSP90, through controlled hyperthermia and $\mathrm{I} / \mathrm{R}$ obtained with the Pringle maneuver or transplantation. In these studies, the intervention group had a significantly greater increase in survival, lower values of released liver enzymes, and less histological liver inflammation and hepatocellular necrosis. ${ }^{(37,38)}$

Chen et al. ${ }^{(39)}$ showed that mice with overexpression of HSP27 are protected against I/R. The protective mechanism involves reduced necrosis and apoptosis of the liver parenchyma, better preservation of the vascular barrier function, and less neutrophil infiltration. Wolf et al. ${ }^{(40)}$ hypothesized that HSP70 plays an important role in liver regeneration after hepatectomy, by performing partial hepatectomy in mice without HSP70. These rats had decreased liver regeneration, and the hypothetical mechanism was that HSP70 contributes to early liver regeneration via potentiation of the expression of tumor necrosis factor-alpha (TNF- $\alpha$ ). Yang et al. ${ }^{(41)}$ demonstrated that the levels of HSP70 and HSP27 were increased in both the I/R and $\mathrm{I} / \mathrm{R}$ groups associated with octreotide, but were especially higher in the latter group. These findings show a possible therapeutic role for octreotide through the upregulation of HSP27 and HSP70. 
Knowing that geranylacetone has HSP-inducing properties, Fudaba et al. ${ }^{(42)}$ analyzed preconditioning with geranylacetone in donor rats after orthotopic liver transplantation. When rats were pre-treated with geranylacetone, an increase in HSP72 and HSP90 was observed after ischemic stress, which was not observed in the absence of ischemia, indicating that geranylacetone acts synergistically with ischemic stress in the liver in inducing the production of HSP, reduces $\mathrm{I} / \mathrm{R}$ and improves the survival rate.

\section{Kidney transplantation}

The intracellular forms of HSP, especially HSP70, have a cytoprotective action and play a role in delaying apoptosis. ${ }^{(43)}$ After cell injury, HSP70s repair damaged proteins and mark those that are not repairable for subsequent removal, preventing the accumulation of these affected tissues. ${ }^{(44)}$

In this way, HSP70 has the ability to maintain cell structure stable and enable cell survival. Heat shock proteins protects mitochondria from oxygen free radicals, maintains stable intracellular levels of adenosine triphosphate (ATP), and prevents excessive calcium influx, which would cause their destruction.

In experimental models of $\mathrm{I} / \mathrm{R}$ kidney injury, HSPs (and particularly HSP70) play a crucial role in restoring the cellular polarity of renal tubular cells and repairing essential proteins, which are involved in stabilizing cytoskeletal structures. In the context of a post-renal transplantation patient, HSP seems to play an even more important role. In this case, insults mediated mainly by immunological factors lead to an imbalance between pro- and anti-oxidant substances, whose final route is tubular interstitial fibrosis, glomerulosclerosis, and vascular destruction. ${ }^{(45)}$

Some studies have shown an important role for HSP27 in this population. High concentrations of HSP27 are present in the medulla, the main renal region to suffer ischemic alterations. HSP27 seems to have the ability to modulate the proliferation of actin filaments, preventing fibrous proliferation in vascular musculature and mesangial cells. ${ }^{(46)}$

\section{Pancreatic transplantation}

With current advances in surgical techniques and immunomodulation strategy, survival after pancreatic transplantation has increased in the last two decades. However, I/R injury resulting from pancreatitis remains a major therapeutic challenge, with an incidence in the range of $17 \%$ to $35 \%$ of these patients. ${ }^{(47)}$
Tumor necrosis factor-alpha is important in cell proliferation and differentiation, as well as in apoptosis and necrosis related to inflammatory processes. Some studies have demonstrated in vitro $\mathrm{I} / \mathrm{R}$ injury mediated by TNF- $\alpha$ secreted by pancreatic acinar cells. ${ }^{(48)}$ This inappropriate secretion results in activation of local inflammatory response, with changes in microcirculation, which perpetuate the cycle of local injury. HSP70 regulates excessive TNF- $\alpha$ secretion, reducing local inflammation.

In a study in pigs undergoing pancreatic islet cell transplantation, the amount of HSP70 rapidly increased, until 3 to 9 days after the transplantation, when the levels of HSP70 were reduced again. ${ }^{(49)}$

Also in animal models, increased expression of HSP70 artificially induced by application of glutamine attenuates the lesion induced by interleukin 1 beta (IL-1 $\beta$ ) in association with the production of nitric oxide (NO), modulating ischemic lesions in islet transplantation. ${ }^{(50)}$

\section{CONCLUSION}

Expression of heat shock protein is associated with inflammatory manifestations and ischemia-reperfusion injury in abdominal organ transplantations. This is a prognostic factor and can influence the graft outcome.

\section{AUTHORS'CONTRIBUTION}

Igor Lepski Calil and Francisco Tustumi: writing the article. Jorge Henrique Bento de Sousa and Bruno Martins Tomazini: literature searching. Ruy Jorge Cruz Jr: methodology. Gustavo Niankowski Saliba: investigation. Rafael Antonio Arruda Pécora: validation. Luiz Augusto Carneiro D'Albuquerque: superision.

\section{AUTHORS' INFORMATION}

Calil IL: http://orcid.org/0000-0002-7734-5491

Tustumi F: http://orcid.org/0000-0001-6695-0496 de Sousa JH: http://orcid.org/0000-0001-6826-6823

Tomazini BM: http://orcid.org/0000-0001-6763-6132

Cruz Jr RJ: http://orcid.org/0000-0001-5290-9978

Saliba GN: http://orcid.org/0000-0002-6613-2044

Pécora RA: http://orcid.org/0000-0002-5820-0828

D`Albuquerque LA: http://orcid.org/0000-0001-7607-7168

\section{REFERENCES}

1. Kampinga HH, Hageman J, Vos MJ, Kubota H, Tanguay RM, Bruford EA, et al. Guidelines for the nomenclature of the human heat shock proteins. Cell Stress Chaperones. 2009;14(1):105-11. 
2. Feder ME, Hofmann GE. Heat-shock proteins, molecular chaperones, and the stress response: evolutionary and ecological physiology. Annu Rev Physiol. 1999:61:243-82. Review.

3. Gething MJ, Sambrook J. Protein folding in the cell. Nature. 1992; 355(6355):33-45. Review.

4. Hartl FU, Martin J. Molecular chaperones in cellular protein folding. Curr Opin Struct Biol. 1995;5(1):92-102. Review.

5. Lindquist S. The heat-shock response. Annu Rev Biochem. 1986;55:1151-91. Review.

6. Grace PA. Ischaemia-reperfusion injury. Br J Surg. 1994;81(5):637-47. Review.

7. Eltzschig HK, Eckle T. Ischemia and reperfusion--from mechanism to translation. Nat Med. 2011;17(11):1391-401. Review.

8. Chouchani ET, Pell VR, Gaude E, Aksentijević D, Sundier SY, Robb EL, et al. Ischaemic accumulation of succinate controls reperfusion injury through mitochondrial ROS. Nature. 2014;515(7527):431-5.

9. Sass DA, Reich DJ. Liver transplantation in the 21st century: expanding the donor options. Gastroenterol Clin North Am. 2011;40(3):641-58. Review.

10. Briceño J, Ciria R, de la Mata M, Rufián S, López-Cillero P. Prediction of graft dysfunction based on extended criteria donors in the model for end-stage liver disease score era. Transplantation. 2010;90(5):530-9.

11. Feng S, Goodrich NP, Bragg-Gresham JL, Dykstra DM, Punch JD, DebRoy MA, et al. Characteristics associated with liver graft failure: the concept of a donor risk index. Am J Transplant. 2006;6(4):783-90. Erratum in: Am J Transplant. 2018;18(12):3085

12. Mallick IH, Yang W, Winslet MC, Seifalian AM. Ischemia-reperfusion injury of the intestine and protective strategies against injury. Dig Dis Sci. 2004;49(9):1359-77. Review.

13. Chen YG, Ashok BT, Liu X, Garikapaty VP, Mittelman A, Tiwari RK. Induction of heat shock protein gp96 by immune cytokines. Cell Stress Chaperones. 2003;8(3):242-8.

14. Crook M. Type 2 diabetes mellitus: a disease of the innate immune system? An update. Diabet Med. 2004;21(3):203-7. Review.

15. Lane N. A unifying view of ageing and disease: the double-agent theory. $J$ Theor Biol. 2003;225(4):531-40.

16. Schulze PC, Yoshioka J, Takahashi T, He Z, King GL, Lee RT. Hyperglycemia promotes oxidative stress through inhibition of thioredoxin function by thioredoxin-interacting protein. J Biol Chem. 2004;279(29):30369-74.

17. Trieb K, Dirnhofer S, Krumböck N, Blahovec H, Sgonc R, Margreiter R, et al. Heat shock protein expression in the transplanted human kidney. Transpl Int. 2001;14(5):281-6

18. Ritossa F. A new puffing pattern induced by temperature shock and DNP in drosophila. Experientia. 1962;18:571-3.

19. Koninkx JF. Protein synthesis in salivary glands of Drosophila hydei after experimental gene induction. Biochem J. 1976;158(3):623-8.

20. Waters ER. Conservative innovation: the mixed-up evolutionary history of the heat-shock proteins. Biochem (Lond). 2014;36(1):9-14. Review.

21. Minor $T$, von Horn $C$. Reduction of renal preservation/reperfusion injury by controlled hyperthermia during ex vivo machine perfusion. Clin Transl Sci. 2021;14(2):544-9.

22. von Horn C, Minor T. Transient hyperthermia during oxygenated rewarming of isolated rat livers. Transpl Int. 2020;33(3):272-8.

23. Boteon $Y L$, Boteon AP. Prospects for the ex situ liver machine perfusion in Brazil. Rev Col Bras Cir. 2020;47:e20202610.

24. Reznik A, Plotnikova 0, Skvortsov A, Skoblov M, Reznik 0, Baranova A. Reperfusion activates AP-1 and heat shock response in donor kidney parenchyma after warm ischemia. Biomed Res Int. 2018;2018:5717913.

25. Fishbein TM. Intestinal transplantation. N Engl J Med. 2009;361(10):9981008. Review. Erratum in: N Engl J Med. 2009;361(14):1416.

26. Benichou G, Tonsho M, Tocco G, Nadazdin 0, Madsen JC. Innate immunity and resistance to tolerogenesis in allotransplantation. Front Immunol. 2012;3:73.

27. Chong AS, Alegre ML. The impact of infection and tissue damage in solidorgan transplantation. Nat Rev Immunol. 2012;12(6):459-71. Review.

28. Lutz J, Thürmel K, Heemann U. Anti-inflammatory treatment strategies for ischemia/reperfusion injury in transplantation. J Inflamm (Lond). 2010;7:27.
29. Ogita K, Hopkinson K, Nakao M, Wood RF, Pockley AG. Stress responses in graft and native intestine after rat heterotopic small bowel transplantation. Transplantation. 2000;69(11):2273-7.

30. Oltean M, Dindelegan G, Kurlberg G, Nilsson O, Karlsson-Parra A, Olausson M Intragraft heat shock protein-60 expression after small bowel transplantation in the mouse. Transplant Proc. 2004;36(2):350-2.

31. Nowak TS Jr. Synthesis of heat shock/stress proteins during cellular injury. Ann N Y Acad Sci. 1993;679:142-56. Review.

32. Vincenti M, Behrends M, Dang K, Park YH, Hirose R, Blasi-Ibanez A, et al. Induction of intestinal ischemia reperfusion injury by portal vein outflow occlusion in rats. J Gastroenterol. 2010;45(11):1103-10.

33. Tashiro S, Miyake H, Rokutan K. Role of geranylgeranylacetone as non-toxic HSP70 inducer in liver surgery: clinical application. J Hepatobiliary Pancreat Sci. 2018;25(5):269-74. Review.

34. Saad S, Kanai M, Awane M, Yamamoto Y, Morimoto T, Isselhard W, et al. Protective effect of heat shock pretreatment with heat shock protein induction before hepatic warm ischemic injury caused by Pringle's maneuver Surgery. 1995;118(3):510-6.

35. Terajima H, Enders G, Thiaener A, Hammer C, Kondo T, Thiery J, et al. Impact of hyperthermic preconditioning on postischemic hepatic microcirculatory disturbances in an isolated perfusion model of the rat liver. Hepatology. 2000;31(2):407-15

36. Conti A, Scala S, D’Agostino P, Alimenti E, Morelli D, Andria B, et al. Wide gene expression profiling of ischemia-reperfusion injury in human liver transplantation. Liver Transpl. 2007;13(1):99-113.

37. Mokuno Y, Berthiaume F, Tompkins RG, Balis UJ, Yarmush ML. Technique for expanding the donor liver pool: heat shock preconditioning in a rat fatty liver model. Liver Transpl. 2004;10(2):264-72.

38. Yamagami K, Yamamoto Y, Kume M, Kimoto S, Yamamoto H, Ozaki N, et al. Heat shock preconditioning ameliorates liver injury following normothermic ischemia-reperfusion in steatotic rat livers. J Surg Res. 1998;79(1):47-53.

39. Chen SW, Park SW, Kim M, Brown KM, D'Agati VD, Lee HT. Human heat shock protein 27 overexpressing mice are protected against hepatic ischemia and reperfusion injury. Transplantation. 2009;87(10):1478-87.

40. Wolf JH, Bhatti TR, Fouraschen S, Chakravorty S, Wang L, Kurian S, et al Heat shock protein 70 is required for optimal liver regeneration after partia hepatectomy in mice. Liver Transpl. 2014;20(3):376-85.

41. Yang J, Sun H, Guan R, Liu W, Xia Y, Zhao J, et al. Hepatocellular protein profiles after hepatic ischemia/reperfusion injury with or without octreotide preconditioning in a rabbit model. Transplant Proc. 2014;46(10):3282-8.

42. Fudaba $Y$, Ohdan $H$, Tashiro $H$, Ito $H$, Fukuda $Y$, Dohi $K$, et al. Geranylgeranylacetone, a heat shock protein inducer, prevents primary graft nonfunction in rat liver transplantation. Transplantation. 2001;72(2):184-9.

43. Nayak Rao S. The role of heat shock proteins in kidney disease. J Transl Int Med. 2016;4(3):114-7. Review.

44. Richter K, Haslbeck M, Buchner J. The heat shock response: life on the verge of death. Mol Cell. 2010;40(2):253-66. Review.

45. Raj DS, Lim G, Levi M, Qualls C, Jain SK. Advanced glycation end products and oxidative stress are increased in chronic allograft nephropathy. Am J Kidney Dis. 2004;43(1):154-60.

46. Kostenko S, Moens U. Heat shock protein 27 phosphorylation: kinases, phosphatases, functions and pathology. Cell Mol Life Sci. 2009;66(20):3289307. Review.

47. Gruessner AC. 2011 update on pancreas transplantation: comprehensive trend analysis of 25,000 cases followed up over the course of twenty-four years at the International Pancreas Transplant Registry (IPTR). Rev Diabet Stud. 2011:8(1):6-16. Review.

48. Binker MG, Cosen-Binker LI. Acute pancreatitis: the stress factor. World $J$ Gastroenterol. 2014;20(19):5801-7. Review.

49. Sandberg J0, Margulis B, Jansson L, Karlsten R, Korsgren O. Transplantation of fetal porcine pancreas to diabetic or normoglycemic nude mice. Evidence of a rapid engraftment process demonstrated by blood flow and heat shock protein 70 measurements. Transplantation. 1995;59(12):1665-9.

50. Jang HJ, Kwak JH, Cho EY, We YM, Lee YH, Kim SC, et al. Glutamine induces heat-shock protein-70 and glutathione expression and attenuates ischemic damage in rat islets. Transplant Proc. 2008;40(8):2581-4. 